\title{
ACESSO À SAÚDE PELA POPULAÇÃO TRANS NO BRASIL: NAS ENTRELINHAS DA REVISÃO INTEGRATIVA
}

\author{
ACCESS TO HEALTH BY THE TRANSSEXUAL POPULATION IN BRAZIL: \\ BETWEEN THE LINES OF THE INTEGRATIVE REVIEW
}
Pablo Cardozo Rocon' (iD) [0000-0003-2696-5786], Kallen Dettmann Wandekoken² (iD) [0000-0002-2326-4880], Maria Elizabeth Barros de Barros ${ }^{3}$ (D) [0000-0003-1123-4374], Marco José Oliveira Duarte ${ }^{4}$ (DD [0000-0002- 6395-1941], Francis Sodré ${ }^{5}$ iD [0000-0003-4037-9388]

\author{
1 Universidade Federal de Mato Grosso, Instituto de Saúde Coletiva, Departamento de Saúde Coletiva, \\ Cuiabá, Mato Grosso, Brasil. <pablocardoz@gmail.com> \\ ${ }^{2}$ Universidade Federal do Espírito Santo, Centro de Ciências da Saúde, Departamento de Enfermagem, \\ Vitória, Espírito Santo, Brasil. \\ ${ }^{3}$ Universidade Federal do Espírito Santo, Centro de Ciências Humanas e Sociais, Departamento de \\ Psicologia, Vitória, Espírito Santo, Brasil. \\ ${ }^{4}$ Universidade Federal de Juiz de Fora, Faculdade de Serviço Social, Departamento de Fundamentos \\ do Serviço Social, Juiz de Fora, Minas Gerais, Brasil. \\ ${ }^{5}$ Universidade Federal do Espírito Santo, Centro de Ciências Jurídicas e Econômicas, Departamento de \\ Serviço Social, Vitória, Espírito Santo, Brasil.
}

Resumo Neste artigo, é realizado um mapeamento da produção científica sobre o acesso à saúde pela população transexual pós-2008, ano importante para a saúde trans no Brasil, no qual foi criado o Processo Transexualizador do Sistema Único de Saúde. O objetivo desse trabalho foi realizar uma revisão integrativa da literatura sobre acesso à saúde da população transexual e travesti brasileira, empregando as bases de dados MEDLINE, LILACS e SciELO, empregando-se os seguintes descritores:'transexualidade,'transexualismo', 'travestismo,' 'travesti' e'transgênero', foram selecionados 22 artigos. Considerando a produção científica analisada, constatamos inúmeros desafios ao acesso da população trans no Sistema Único de Saúde, como a discriminação, a patologização da transexualidade, a falta de qualificação dos profissionais, o acolhimento inadequado, a escassez de recursos para o financiamento de políticas e programas voltados ao combate à discriminação de origem homofóbica e trans-travestifóbica, bem como a ausência da garantia de serviços específicos - como o processo transexualizador.

Palavras-Chave revisão integrativa; acesso à saúde; travesti; transexual.
Abstract The article presents a mapping of the scientific production regarding the access to health by the transsexual population after 2008, an important year for trans health in Brazil, in which the Transsexualizing Process of the Brazilian Unified Health System (Processo Transexualizador do Sistema Único de Saúde, in Portuguese) was created. The goal of the present work was to conduct an integrative review of the literature regarding the access to health by the Brazilian transsexual and transvestite population in the MEDLINE, LILACS and SciELO databases, using the following descriptors: 'transsexuality,'transsexualism,'transvestitism,"transvestite' and 'transgendered', and 22 articles were selected. Considering the scientific production analyzed, we verified countless challenges regarding the access of the trans population to the Brazilian Unified Health System, such as discrimination, pathologization of transsexuality, lack of training on the part of the professionals, improper embracement, lack of resources to fund policies and programs geared towards the fight against discrimination due to homophobia or tans/transvestite-phobia, as well as the lack of guarantee of specific services - such as the transsexualizing process. Keywords integrative review; access to health; transvestite; transsexual. 


\section{Introdução}

Em 1997, por meio da Resolução n. 1.482/97, o Conselho Federal de Medicina (CFM) em complemento ao Código de Ética Médica passa a autorizar - a título experimental - a cirurgia de transgenitalização no Brasil. A Resolução foi revogada em 2002 e em 2010 pela Resolução n. 1.955. As Resoluções estabelecem como critério para eleição à cirurgia a pessoa ser transexual e portadora de "desvio psicológico permanente de identidade sexual com rejeição do fenótipo e tendência à automutilação e/ou autoextermínio" (Conselho Federal de Medicina, 2010). Estabeleceu-se, ainda, que a eleição para a possibilidade de realização da cirurgia ficava sob condição da pessoa transexual submeter-se à avaliação de uma equipe multiprofissional por, no mínimo, dois anos de acompanhamento conjunto (Conselho Federal de Medicina, 2010).

Segundo o Art. 196 da Constituição Federal de 1988, a saúde é direito de todos e dever do Estado. Este deve garantir o acesso universal e igualitário às ações e aos serviços de promoção, proteção e recuperação da saúde. No entanto, a garantia de acesso universal e igualitário ainda se constitui um desafio em diferentes cenários, para os diversos sujeitos que demandam por atendimentos de saúde em suas especificidades. Dentre aqueles que enfrentam cotidianamente os desafios de acesso e a garantia de promoção, proteção e recuperação de sua saúde, encontra-se a população trans - transexuais, travestis e transgêneros.

O Sistema Único de Saúde (SUS) conta com políticas direcionadas a este público, como a Política Nacional de Saúde Integral de Lésbicas, Gays, Bissexuais, Travestis e Transexuais (LGBT) e, mais especificamente, o Processo Transexualizador do SUS, criado em 2008 e redefinido e ampliado em 2013 (Brasil, 2008; 2013). Apesar da importante iniciativa do Ministério da Saúde em publicar Portarias e instituir serviços de saúde específicos a essa população, ela continua sendo apontada como a que mais enfrenta dificuldades para acessar os serviços de saúde, da atenção básica à alta complexidade, dentre toda a população LGBT (Mello et al., 2011).

Nessa direção, este artigo se propôs a analisar os desafios para a garantia da universalização do acesso à saúde pela população transexual e travesti no Brasil baseado numa revisão integrativa da literatura.

\section{Método}

A revisão integrativa foi realizada por meio de uma pesquisa eletrônica, em novembro de 2018, usando as bases de dados MEDLINE, LILACS e SciELO, empregando-se os seguintes descritores: 'transexualidade', 'transexualismo', 'travestismo,' 'travesti' e'transgênero'. Segundo Paula, Padoin e Galvão (2016), os estudos incluídos na revisão integrativa permitem uma 
avaliação crítica do tema escolhido e, dessa forma, é possível identificar lacunas que poderão sugerir e direcionar pesquisas futuras.

Os critérios de inclusão foram artigos completos que abordavam o tema 'acesso à saúde da população transexual e travesti brasileira', publicados entre janeiro de 2008 - ano em que foi criado o Processo Transexualizador do Sistema Único de Saúde (Brasil, 2008), e dezembro de 2017. Consideraram-se artigos escritos nas línguas espanhola, inglesa e portuguesa que analisassem o acesso à assistência à saúde por travestis e transexuais no Brasil. Foram excluídos estudos que não investigassem o tema proposto, artigos de revisão, e que não atendessem aos critérios de inclusão requeridos.

Na primeira etapa, a intenção foi identificar trabalhos que abordassem o tema em questão e se os mesmos preenchiam os critérios descritos acima, sendo selecionados 188 artigos mediante leitura de títulos e resumos. Na segunda etapa, realizou-se a leitura na íntegra destes 188 artigos empregando os critérios de inclusão e exclusão, chegou-se à seleção de 22 artigos. Caso houvesse discordância entre os avaliadores sobre os critérios analisados, era realizada discussão específica sobre o artigo em questão, confrontando ideias com base nos critérios adotados para a revisão.

\section{Resultados e Discussão}

Os resultados são apresentados considerandoas principais categorias apontadas nos artigos analisados durante a revisão integrativa. Para extração dos dados, foi usado um instrumento de coleta com os seguintes itens: ano; autores;periódico;objetivo;enfoquemetodológico;técnica/instrumento;edesafios no acesso à saúde da população trans.

Dos 22 artigos selecionados, 2 foram publicados em 2008 (Lionço, 2008; Romano, 2008); 6 entre 2009 e 2012 (Arán, Murta e Lionço, 2009; Arán e Murta, 2009; Lionço, 2009; Mello et al., 2011; Sampaio e Coelho, 2012; Bento, 2012); 14 de 2013 até 2017 (Almeida e Murta, 2013; Freire at al., 2013; Borba, 2014; Souza et al., 2014; Souza et al., 2015; Souza e Pereira, 2015; Rocon et al., 2016; Lima e Cruz, 2016; Ferreira et al., 2017; Silva e Mello, 2017; Pinto et al., 2017; Popadiuk, Oliveira e Signorelli, 2017; Sehnem et al., 2017; Spizziri, Ankier e Abdo, 2017). Pode-se perceber um aumento no número de artigos científicos publicados após a criação da Política Nacional de Saúde Integral de LGBT em 2011 (Brasil, 2011) e da ampliação do Processo Transexualizador do SUS que ocorreu em 2013 (Brasil, 2013). Sugerindo que tais políticas podem ter contribuído para a visibilidade das necessidades em saúde da população trans, negligenciadas pelo Estado brasileiro até 2008, quando foi criado o Processo Transexualizador do SUS, único programa de atenção às demandas em saúde específicas da população trans no Brasil. Observa-se ainda que há 
repetição de autores nas publicações coletadas, o que evidencia que a produção acadêmica nesta área temática se mantém concentrada entre os mesmos pesquisadores, com variação maior em 2017.

Além disso, nota-se que há pouca variedade em relação aos periódicos, de forma que a maioria dos artigos foi publicada em revistas da área da Saúde Coletiva, com exceção de 03 artigos publicados em revista da área de enfermagem (Souza e Pereira, 2015; Sehnem et al., 2017; Pinto et al., 2017) e 01 em revista da área médica (Spizziri, Ankier e Abdo, 2017). Tal fato pode se justificar tendo em vista que a área da Saúde Coletiva se constituiu num campo científico transdisciplinar, agregando diversas formas de produção e campos de conhecimento (ciências humanas e sociais, política planejamento e gestão, epidemiologia, pesquisas clínicas etc.).

Evidencia-se também que dentre os 22 artigos selecionados, 06 são artigos teóricos (Lionço, 2008; Arán e Murta, 2009; Arán, Murta e Lionço, 2009; Lionço, 2009; Almeida e Murta, 2013; Freire et al. 2013; Spizziri, Ankier e Abdo, 2017), 01 relato de experiência (Romano, 2008), 01 pesquisa com 10 enfermeiros (Sehnem et al., 2017), 01 pesquisa com 09 psicólogos (Silva e Mello, 2017), 01 pesquisa de campo com abordagem qualitativa em que realizou-se entrevistas com gestores e integrantes da sociedade civil organizada (Mello et al., 2011), 01 pesquisa documental com método quantitativo e qualitativo (Popadiuk, Oliveira e Signorelli, 2017), 05 pesquisas de campo com até 15 pessoas trans (transexuais e travestis) (Bento, 2012; Sampaio e Coelho, 2012; Borba, 2014; Lima e Cruz, 2016; Rocon et al., 2016; Ferreira et al., 2017), além de 03 pesquisas de campo realizadas com 49 travestis por meio de entrevistas em profundidade e observação participante - que parecem se tratar de recortes de uma mesma pesquisa empírica (Souza et al., 2014; Souza e Pereira, 2015; Souza et al., 2015) e uma pesquisa realizada com 40 mulheres transexuais cadastradas no Processo Transexualizador de um município do Rio de Janeiro (Pinto et al., 2017).

Após a categorização detalhada do conteúdo dos 22 artigos selecionados, foram identificadas 13 categorias que tratam de ideias em comum em relação aos desafios no acesso à saúde da população trans no Brasil, apresentadas abaixo no Quadro 1: 
Quadro 1

\begin{tabular}{|c|c|c|c|}
\hline Item & Categorias & $\mathbf{N}$ & Autores/Ano \\
\hline 01 & $\begin{array}{l}\text { Discriminação nos serviços e } \\
\text { equipamentos de saúde/ Sentidos } \\
\text { para a transexualidade. }\end{array}$ & 13 & $\begin{array}{l}\text { Lionço (2008); Romano (2008); Arán, Murta e Lionço (2009); } \\
\text { Lionço (2009); Mello et al. (2011); Almeida e Murta (2013); } \\
\text { Freire et al. (2013); Souza et al. (2014); Rocon et al. (2016); } \\
\text { Souza et al. (2015); Souza e Pereira (2015); Sampaio e Coelho } \\
\text { (2012); Ferreira et al. (2017). }\end{array}$ \\
\hline 02 & Patologização da transexualidade. & 11 & $\begin{array}{l}\text { Lionço (2008); Arán, Murta e Lionço (2009); Lionço (2009); } \\
\text { Arán e Murta (2009); Sampaio e Coelho (2012); Bento (2012); } \\
\text { Almeida e Murta (2013); Freire et al. (2013); Borba (2014); } \\
\text { Rocon et al. (2016); Lima e Cruz (2016); Silva e Mello (2017); } \\
\text { Pinto et al. (2017); Popadiuk, Oliveira e Signorelli (2017). }\end{array}$ \\
\hline 03 & Acolhimento inadequado. & 06 & $\begin{array}{l}\text { Romano (2008); Arán, Murtae Lionço (2009); Souza et al. } \\
\text { (2014); Souza e Pereira (2015); Souza et al. (2015); Lima e } \\
\text { Cruz (2016); Sehnem et al. (2017). }\end{array}$ \\
\hline 04 & $\begin{array}{l}\text { Exigência de cirurgia para troca de } \\
\text { nome e sexo em documentos. }\end{array}$ & 06 & Arán, Murta e Lionço (2009); Almeida e Murta (2013) \\
\hline 05 & $\begin{array}{l}\text { Falta de qualificação dos } \\
\text { profissionais. }\end{array}$ & 04 & $\begin{array}{l}\text { Souza e Pereira (2015); Souza et al. (2015); Arán e Murta } \\
\text { (2009); Sampaio e Coelho (2012); Sehnem et al. (2017); } \\
\text { Spizziri, Ankier e Abdo (2017). }\end{array}$ \\
\hline 06 & $\begin{array}{l}\text { Ausência de política de atenção } \\
\text { básica/ Rede de saúde inexistente. }\end{array}$ & 02 & Arán e Murta (2009); Lima e Cruz (2016) \\
\hline 07 & Escassez de recursos. & 02 & Mello et al. (2011); Almeida e Murta (2013) \\
\hline 08 & $\begin{array}{l}\text { Ausência de reconhecimento } \\
\text { identitário nas políticas públicas. }\end{array}$ & 01 & Lionço (2009) \\
\hline 09 & $\begin{array}{l}\text { Entraves nas relações entre } \\
\text { governos estaduais, municipais } \\
\text { e federal. }\end{array}$ & 01 & Mello et al (2011) \\
\hline 10 & $\begin{array}{l}\text { Ausência de atenção } \\
\text { multiprofissional. }\end{array}$ & 01 & Almeida e Murta (2013) \\
\hline 11 & Homogeneização discursiva. & 01 & Borba (2014) \\
\hline 12 & $\begin{array}{l}\text { Foco na tecnologia dura e leve- } \\
\text { dura. }\end{array}$ & 01 & Lima e Cruz (2016) \\
\hline 13 & Falta de acesso à hormonização. & 01 & Lima e Cruz (2016) \\
\hline
\end{tabular}

Para fins de análise e melhor apresentação deste artigo, optou-se por se ater à discussão das categorias identificadas em mais de uma publicação. Assim, as categorias que correspondem aos itens de 08 a 13, apesar de terem sido identificadas e de estarem relacionadas no Quadro 1, não serão discutidas. Segue a análise das categorias que correspondem aos itens 01 a 07. 


\section{Discriminação nos serviços e equipamentos de saúde/ Sentidos para a tran- sexualidade}

Treze artigos enfatizam a discriminação como desafio ao acesso à saúde pela população trans. Rocon et al. (2016) destacam que apesar da Carta dos Direitos dos Usuários do SUS ter sido publicada em 2006 afirmando que todo cidadão tem direito ao atendimento humanizado, acolhedor e livre de qualquer discriminação (Brasil, 2006), estas questões ainda estão longe de serem atendidas. Na pesquisa realizada com 15 pessoas trans, os autores retratam trechos das entrevistas que apontam fortes sentimentos de tristeza e de angústia frente à discriminação vivenciada nos serviços de saúde, o que repercute em abandono dos tratamentos em andamento e resistência na busca por cuidados em saúde quando necessários (Rocon et al., 2016). Ou seja, situações de discriminação vivenciadas em locais onde elas deveriam ser amenizadas. Rocon et al. (2016) exemplificam a discriminação com base no desrespeito ao nome social nos serviços de saúde, e Souza et al (2015) destacam as situações de violência por meio de 'chacota', humilhação, discriminação, entre outras situações - o que leva a população trans a evitar adentrar os equipamentos e serviços de saúde, o que reflete na piora de suas condições de saúde.

Ferreira et al. (2017) entrevistaram seis travestis que residem em Teresina a fim de compreenderem suas vivências acerca da atenção à saúde no SUS. Os autores enfatizam que a discriminação foi mencionada por todas as participantes, concluindo que os fatos narrados refletem os valores heteronormativos presentes na sociedade.

Na pesquisa etnográfica de Souza et al. (2015), as travestis relataram situações de violência, humilhação, julgamento moral e desrespeito ao nome social. Assim, segundo o estudo, diante da vivência do sofrimento na busca por serviços de saúde, as travestis dificilmente se dirigem às instituições de saúde, mesmo em casos graves.

Lionço (2008) destaca que essa discriminação ainda é subestimada, mesmo considerando que esta seja um ponto-chave para exclusão e negação do acesso à saúde. Romano (2008) enfatiza que as pessoas trans são estigmatizadas e vivenciam preconceito no cotidiano de saúde, de forma a não possibilitar garantias fundamentais como a equidade - como se tivessem menos direitos (Freire et al., 2013), ferindo assim o princípio da universalidade do acesso à saúde (Ferreira et al., 2017).

Lionço (2009) e Souza et al. $(2014 ; 2015)$ afirmam que as práticas discriminatórias, muitas vezes, são pautadas nos estereótipos de gênero engendrados pela heteronormatividade, e legitimadas pelos discursos religiosos - que consideram as pessoas trans pecadoras -, ou médicos-científicos - que as 
conceituam como doentes-. Lionço (2008) e Souza et al. (2015) acrescentam que essas práticas discriminatórias têm refletido em sofrimento psíquico.

Na pesquisa de Mello et al. (2011), gestores e ativistas entrevistados destacam que ainda há muito o que ser feito para a redução das situações de discriminação nos serviços de saúde. Os autores também pontuam que dentre a população LGBT, o segmento trans é o que enfrenta maiores dificuldades na busca por serviços de saúde, tanto pelas demandas específicas como no acesso aos serviços transexualizadores, como pelos episódios de trans-travestifobia presentes no cotidiano dos equipamentos de saúde.

Neste ponto, Lionço (2008) e Arán, Murta e Lionço (2009) são enfáticas ao apontar que para que haja redução nos processos discriminatórios frente à população trans se faz necessária a compreensão da diversidade em relação às possibilidades eróticas e subjetivas, de modo que se busque o respeito à singularidade dos sujeitos e não a normatização de suas vidas. Nessa direção, Freire et al. (2013) destacam a importância da publicação da Política Nacional de Saúde Integral de LGBT que advoga em favor do acesso à saúde, livre de discriminação e com direito ao nome social. Por fim, Rocon et al. (2016) afirmam que avançar na produção e na promoção de serviços, programas e ações em saúde para a população requer afirmar princípios ético-políticos da reforma sanitária brasileira, como equidade, integralidade e universalidade.

\section{Patologização da transexualidade}

Arán, Murta e Lionço (2009) destacam que a prática clínica em geral tem sido pautada na psiquiatrização da transexualidade, que a considera como 'transtorno deidentidade degênero', sendoesta uma condição para oacesso à saúde e exercício da cidadania. As autoras ponderam que embora a psiquiatrização tenha proporcionado visibilidade às pessoas trans e legitimidade à cirurgia de redesignação sexual como questão de saúde, ela reforça a exclusão social em virtude de seu caráter patologizante, desconsiderando os aspectos históricos, políticos e subjetivos da transexualidade (Arán, Murta e Lionço, 2009; Arán e Murta, 2009; Almeida e Murta, 2013).

Lima e Cruz (2016) mencionam que no atual Manual de Diagnóstico e Estatístico de Transtornos Mentais - $5^{\text {a }}$ edição (DSM-V) a transexualidade é entendida como disforia de gênero, o que provocou opiniões divergentes: alguns acreditam que houve um avanço na despatologização, uma vez que a transexualidade deixa de ser entendida como transtorno; outros pensam que a patologização se mantém sob nova nomenclatura. Para as autoras, essa evidente contínua patologização contribui para despotencializar as singularidades das pessoas trans. 
Arán, Murta e Lionço (2009) e Sampaio e Coelho (2012) analisam que a patologização da transexualidade decorre das concepções normativas pautadas no binarismo heterossexual que busca regular as sexualidades e subjetividades. Rocon et al. (2016) identificaram essas concepções na definição da transexualidade nas resoluções do CFM que definem os critérios para seleção de pacientes para os procedimentos de hormonioterapia e cirurgias de redesignação sexual, na medida em que elas definem a transexualidade como condição de ojeriza ao próprio corpo pela dissonância com o binarismo dos gêneros, tendendo a 'automutilação e/ou autoextermínio'.

Bento (2012) argumenta que a patologização da transexualidade tem como fundamento a associação dos gêneros à presença de estruturas biológicas e corporais como as genitálias. Essa associação precisa ser compreendida como um padrão normativo social - binarismo dos gêneros - que define homens pela presença do pênis e, assim, comportamentos sociais definidos sob signos da masculinidade (padrões de comportamento e gostos por determinadas roupas, práticas esportivas, cores etc.), e as mulheres pela presença da vagina, com sua vida social regulada sob signos de feminilidade (Bento, 2006). Há também um segundo elemento na associação entre gêneros e estruturas biológicas, a heteronormatividade, segundo a qual "a heterossexualidade aparece, assim, como o padrão para avaliar todas as outras sexualidades" (Borrillo, 2010, p. 31).

Para Bento (2012), a heteronormatividade e o gênero binário têm sido parâmetros no processo de seleção dos serviços de saúde por um diagnóstico que considera estereótipos de feminilidade e masculinidade. Nessa direção, Bento (2006) discute a ausência de neutralidade dos trabalhadores da saúde no processo de diagnóstico, de modo que seriam selecionados, para acessar os serviços transexualizadores, usuários/as considerados/as 'transexuais de verdade'- pessoas trans que correspondessem às perspectivas de gênero da equipe multiprofissional fundadas no gênero binário e heteronormativo.

Arán e Murta (2009) discutem a necessidade do diagnóstico de 'Transtorno de Identidade de Gênero' como condição de acesso à saúde pela população trans e afirmam que a ideia do 'transexual verdadeiro' aponta fortemente a homofobia no discurso médico.

Lionço (2008) ressalta que a associação entre direitos sexuais e a 'saúde sexual', por meio da medicalização das diferenças, contribui para que a transexualidade seja entendida como patologia, repercutindo muitas vezes em situações discriminatórias como já apontado no item anterior. A autora também acrescenta que a patologização da transexualidade é um dos fatores que pode proporcionar o adoecimento e sofrimento dessa população por contribuir com sua marginalização e exclusão social (Rocon et al., 2016). Foucault (2010a e 2010b) analisa o uso do discurso médico e a constituição 
dos anormais como estratégia histórica para exclusão social de grupos populacionais, de modo que ao serem definidos como anormais se constituíam em ameaça à saúde da população, recebendo, como respostas do Estado, ações medicalizadoras de correção, discriminatórias e normalizadoras- resgate à norma -, ou eram 'deixados para morrer'. Nessa direção, Butler (2009) aponta que receber um diagnóstico como o de transtorno de identidade de gênero, é ser "considerado doente, errado, disfuncional, anormal e sofrer uma certa estigmatização em consequência desse diagnóstico" (p. 96).

Rocon et al. (2016) evidenciaram o diagnóstico como dificultador para o acesso à saúde, na medida em que é exigido dos/as usuários/as a reprodução das perspectivas de gênero dos profissionais da saúde. Lionço (2009) afirma que no Processo Transexualizador os candidatos são avaliados a fim de que a cirurgia seja ou não autorizada. Para tanto, são empregados mecanismos de poder e de normatização das condutas para que se conclua quem são os 'transexuais verdadeiros', ou seja, para que se avalie os níveis ideais de feminilidade e de masculinidade. Assim, as pessoas trans que não atendam aos estereótipos de gênero têm seu acesso negado aos serviços de saúde oferecidos pelos processos transexualizadores, assim como lhe é negada a livre expressão da personalidade.

Pinto et al. (2017), entrevistaram mulheres transexuais que afirmam não entenderem a transexualidade como patologia, mas que se submetem a esta condição a fim de ter acesso ao Processo Transexualizador. Questões estas que, de fato, comprometem a autonomia e o controle dos próprios corpos. Rocon et al. (2016) também apresentam trechos de entrevistas nos quais as participantes narraram se usar 'truques' (vestimentas, maquiagem, padrões de comportamento e discursos embasados pela leitura dos manuais de diagnóstico) a fim de convencer os profissionais da saúde da veracidade de sua transexualidade.

Lionço (2008) enfatiza que na busca pelo direito à saúde se faz necessária a desmedicalização do discurso sobre gênero e sexualidade, de forma a avançar frente ao modelo biomédico de atenção à saúde que exige a existência de uma patologia prévia como condição de acesso e, assim, se buscar consolidar outros discursos sobre a sexualidade como sendo legítimos - questão esta também apontada por Arán, Murta e Lionço (2009) ao citarem Butler a fim de afirmar que a patologização enfraquece o que a filósofa denomina de transautonomia.

Portanto, implica, assim, em discutir a autonomia e reconhecer as diferenças no âmbito do gênero como uma possibilidade plausível não determinada pela congruência entre identidade de gênero e sexo anatômico (Lionço, 2008; Arán, Murta e Lionço, 2009). E, ainda, considerar que a transexualidade vai muito além das questões pré e pós-operatórias (Arán, 
Murta e Lionço, 2009). Lionço (2009) acrescenta que a ideia de patologia expressa a necessidade de cirurgia para a adequação dos corpos. Assim, como as travestis não demandam essa 'correção' são ainda mais excluídas do acesso aos serviços de saúde, em especial dos procedimentos de modificação corpórea.

Lionço (2009) ressalta que em reunião do Comitê Técnico de Saúde da População GLTB (gays, lésbicas, transgêneros e bissexuais) - instituído pela Portaria GM n².227/2004 - sobre o Processo Transexualizador no SUS, ocorrida em 2006, foi enfatizada a despatologização da transexualidade a fim de considerar a autonomia das pessoas trans na condução de suas vidas, de modo que o cuidado em saúde não dependa de normatizações sobre os corpos. No entanto, conselhos de classe como o CFM se mantêm omissos em relação a este debate e continuam aderindo às ideias patológicas, o que repercute na atuação de psicólogos e demais profissionais da saúde.

Rocon, Sodré e Rodrigues (2016) evidenciam a história do processo transexualizador do Brasil marcada pelo discurso medicalizador da transexualidade e o destaque das resoluções do CFM na organização dos processos de trabalho em saúde nesses programas, na medida em que, apesar do Processo Transexualizador do SUS ter sido criado em 2008, desde 1997 tais serviços são oferecidos e organizados no Brasil com base nas diretrizes colocadas por tais resoluções.

Rocon et al. (2016) problematizam, em diálogo com Berenice Bento e Larissa Pelúcio, que apesar de segmentos do movimento social defenderem a patologização da transexualidade como concessão e estratégia política para garantia do acesso à saúde, a Constituição Federal de 1988 afirma que a existência de patologia não pode ser condição para acesso aos serviços de saúde. A patologização, assim, se revela como paradoxo na medida em que, apesar de servir como estratégia política para garantia do acesso, ela exclui diversas pessoas trans dos programas transexualizadores pelo processo diagnóstico.

Borba (2014) argumenta a despatologização como necessária para a humanização do cuidado em saúde para a população trans, de modo que é preciso valorizar as histórias de vida e resistência e, assim, rejeitar a normatização das vivências pela classificação psiquiátrica (Lionço, 2009; Borba, 2014). Almeida e Murta (2013) ressaltam que a despatologização em si não é eficaz como estratégia para contribuir com a atenção integral à saúde das pessoas trans - é preciso criar condições para o acesso à saúde e fortalecer uma atenção multiprofissional, caso contrário, significará um retorno aos processos de exclusão. 


\section{Acolhimento inadequado}

Seteartigosdestacaramoacolhimentocomoproblemática.SegundoRibeiro e Castro (2011, p. 183):

A diretriz Acolhimento, constitutiva dos modos de se produzir saúde como ato ou efeito de acolher, implica uma atitude de inclusão e é também um dispositivo de qualificação da escuta, vínculo, e acesso responsável. Predispondo à conversa, interlocução e ao diálogo, permite ao grupo entender as necessidades de saúde apresentada e responsabilizar-se pelas pessoas que o procuram, buscando a solução do problema real e criando a possibilidade do fortalecimento da rede de atenção.

Aqui, nomeia-se inadequado o acolhimento que impede a inclusão e a escuta qualificada das demandas em saúde da população trans usuária dos serviços de saúde. Nesse sentido, não há acolhimento ou este é inadequado na medida em que o desrespeito às identidades de gênero da população trans vai se materializando no cotidiano dos serviços de saúde pelo desrespeito ao nome social e outras formas de manifestação de transfobia e travestifobia.

Arán, Murta e Lionço (2009) destacam que esta situação dificulta o acesso a estes serviços de forma a excluir a população trans do sistema de saúde. Segundo Romano (2008), mesmo com a campanha em 2004 realizada pelo Ministério da Saúde sobre respeito às identidades trans com os profissionais de saúde, bem como a criação do programa 'Brasil sem Homofobia' no mesmo ano, "ambas as iniciativas, embora tenham causado certo impacto pelo seu ineditismo, não mantiveram um compromisso com a continuidade, prejudicando assim, sua amplitude de eficácia junto ao SUS" (p. 216).

Souza et al. (2014) e Souza e Pereira (2015) com base em pesquisa etnográfica, acrescentam que diante do contexto de ausência de acolhimento nos serviços de saúde, as travestis optam por frequentar as 'casas de santo', onde encontram respeito e não se sentem pressionadas diante da normatização dos corpos tão evidente nos serviços públicos orientados pelo modelo heteronormativo. Assim, esse itinerário propicia um cuidado em saúde sem julgamento e acolhedor.

Do mesmo modo, ao pesquisar o itinerário de cuidados em saúde das travestis, Souza e Pereira (2015) percorreram os espaços mais frequentados pelas participantes e perceberam que elas raramente buscam os serviços de saúde, evidenciando vários relatos sobre ausência de acolhimento e, assim, a dificuldade de acesso aos serviços. Os autores destacam a fala de uma das entrevistas quando a mesma afirma: "a saúde não é diferente do dia a dia. Tratam a gente como não humana, por isto eu não vou ao SUS, de jeito nenhum" (p.150). 
Romano (2008), com base na vivência da pesquisadora com um grupo de travestis no decorrer de seis anos, na busca pela garantia do acesso à saúde desta população, se apoia na constatação de que este tem se pautado em várias formas de discriminação que podem ser efeitos de um despreparo ou desrespeito dos trabalhadores da saúde com a população trans, resultando absenteísmo, em abandono dos tratamentos em saúde em andamento, e resistência em procurar serviços de saúde quando do adoecimento.

Como estratégia para a melhoria do acolhimento, Arán, Murta e Lionço (2009) sugerem o respeito ao nome social como primordial. Já Romano (2008) acrescenta a necessidade da garantia de acesso imediato às consultas mediante agendamento prévio, a garantia do tratamento das travestis com o emprego do artigo feminino (oral e escrito em prontuários) e não usar discursos que contribuem para o preconceito. Já Lima e Cruz (2016) destacam ser necessário que as diferenças sejam acolhidas para que o cuidado em saúde seja satisfatório.

\section{Exigência de cirurgia para troca de nome e sexo}

Arán, Murta e Lionço (2009) afirmam ser essencial a desvinculação entre a exigência de cirurgia e a alteração do registro civil, até porque essa possibilidadepoderiasolucionar,em muitoscasos, váriosconflitoscotidianosenfrentados pelas pessoas trans. As autoras destacam que a cirurgia nem sempreé uma intervenção requerida por essa população, uma vez que existem necessidades distintas, conforme a singularidade de cada indivíduo.

Almeida e Murta (2013) afirmam que a desvinculação da exigência de cirurgia para a realização judicial da troca de nome e sexo nos documentos, tende a facilitar o acesso à saúde pelas pessoas trans. Segundo os autores, apesar de terem realizado os procedimentos de transição, existem pessoas trans que ainda esperam anos para alteração do registro civil, o que repercute em agravos em suas vidas sociais e discriminações até mesmo nos serviços de saúde.

Esses artigos relatam um dilema que antecede a decisão do Conselho Nacional de Justiça em 2018 (Provimento n. 73) que autorizou pessoas trans à alteração de registro civil (prenome e gênero) nos cartórios brasileiros, independente da realização de cirurgia de redesignação sexual. Uma importante vitória para a cidadania da população trans no Brasil.

\section{Falta de qualificação dos profissionais}

Em pesquisa de Souza e Pereira (2015) as travestis afirmam que, muitas vezes, não têm seu nome social respeitado nos serviços de saúde, apesar de haver legislação que determina esta conduta - o que talvez expresse a ausência de entendimento relacionado à legislação específica por parte 
dos profissionais. Além disso, a pesquisa destaca que a falta de qualificação dos profissionais fica evidente quando as travestis buscam o serviço para demandas relacionadas ao processo de transição no gênero, como para requerer auxílio nos cuidados com o silicone e no uso dos hormônios - situações estas desconhecidas por vários profissionais.

Já as transexuais entrevistadas na pesquisa de Sampaio e Coelho (2012), reivindicam que profissionais da psicologia, em especial, sejam capacitados para que não favoreçam situações de discriminação e sentimentos de exclusão, que acontecem em casos de tentativa de cura da transexualidade ou encorajando a desistência da realização dos procedimentos transexualizadores. Questões como estas também foram apontadas por Spizzirri, Ankier e Abdo (2017).

Neste contexto, Arán e Murta (2009) mencionam que um dos problemas para a efetivação do processo transexualizador é a necessidade de capacitação das equipes de saúde com foco na humanização com fins de combater as situações de discriminação vivenciadas pela população usuária. Sehnem et al. (2017) destacam que para a melhoria do acesso se faz necessário o investimento no acolhimento das pessoas trans na atenção primária, o que só será realizado com a qualificação dos profissionais de saúde. Do mesmo modo, Souza et al. (2015) sugere que para a redução nos altos índices de violência e sofrimento vivenciados pelas pessoas trans, se faz necessário focar na formação dos profissionais de saúde.

\section{Ausência de política de atenção básica}

Apesar das portarias do Ministério da Saúde, tanto a de 2013, que amplia o processo transexualizador do SUS, como a de 2011, que institui a Política Nacional de Saúde LGBT, preverem uma política de atenção básica, essa não tem sido efetivada mesmo após a publicação.

Arán e Murta (2009) chamam atenção para a ausência de redes oficiais de referência e contrarreferência entre atenção básica e processo transexualizador como limitadora do acesso. Neste contexto, Lima e Cruz (2016) mencionam que essa ausência de articulação entre atenção básica, ambulatórios e hospitais contribui para o aumento nas filas de espera de usuários por serviços transexualizador. A ausência dessa articulação faz com que demandas que poderiam ser acompanhadas pela atenção básica cheguem até a média e alta complexidade nos serviços transexualizadores, resultando em longas filas de espera por atendimento (Rocon, 2018). 


\section{Escassez de recursos}

Entre os artigos analisados, Almeida e Murta (2013) e Mello et al. (2011) apontaram a escassez de recursos como desafio para o acesso à saúde pelas pessoas trans.

Almeida e Murta (2013) destacam que, apesar da crescente procura pelos serviços referentes ao processo transexualizador disponíveis no SUS, este tem apresentado número de vagas inferior ao necessário em virtude do recebimento de recursos insuficientes à manutenção e ampliação do programa. Nesse cenário, a demanda tende a aumentar, uma vez que é quase inexistente a cobertura pelo setor privado na oferta dos procedimentos transexualizadores, bem como a realidade de insuficiência financeira vivida por parcela importante da população trans para arcar com os custos da transição no gênero por meio da medicina privada (Rocon et al., 2017).

Mello et al. (2011) evidenciam a ausência de recursos para que as ações previstas nas políticas e iniciativas dos governos sejam realizadas. Assim, apesar da criação de políticas e ações importantes como o 'Programa Brasil sem Homofobia' e o 'Plano Nacional de Promoção da Cidadania e Direitos Humanos de LGBT', estas acabam por não se efetivarem em razão da inexistência de previsão orçamentária para que as ações sejam executadas.

\section{Considerações finais}

Com base na presente revisão integrativa, constataram-se sete principais desafios à garantia do acesso universal ao SUS pela população trans: a discriminaçãonosserviçoseequipamentosdesaúde;apatologizaçãodatransexualidade, oacolhimento inadequado; a exigência de cirurgia; a qualificação dos profissionais; a ausência de política de atenção básica e inexistência de rede de saúde; e a escassez de recursos para o financiamento dos processos transexualizadores e de políticas de promoção da equidade e respeito às identidades de gênero trans.

Quando se observam os estudos em torno das discussões sobre discriminação nos serviços e equipamentos de saúde pelos sentidos para a transexualidade produzidos por matrizes heteronormativas e binárias para as compreensões dos gêneros, os estudos evidenciam um 'efeito cascata' na produção de sofrimento e adoecimento na população trans. Os mesmos estudos que afirmam o desrespeito ao nome social e outras expressões da trans-travestifobia institucional dos serviços de saúde, como principal barreira de acesso, também apontam o abandono de importantes tratamentos em andamento, como, por exemplo, infecções sexualmente transmissíveis e HIV, e processos de adoecimento pelo uso de hormônios sem acompanha- 
mento médico, dadas as dificuldades de acessar e permanecer nos serviços de saúde, bem como o pequeno número de serviços em saúde trans-específicos que atendam as demandas em saúde por transformação do corpo.

O diagnóstico de transexualismo também tem sido exaustivamente apontado como importante barreira de acesso aos serviços de saúde, uma vez que esse fortalece concepções sobre gênero e sexualidade que apontam a população trans como anormal, fortalecendo sua marginalização (Butler, 2009). Contudo, é preciso destacar que há uma lacuna de estudos que apontem alternativas a dependência do diagnóstico no processo de trabalho nos processos transexualizadores.

Apesar da formação profissional ser apontada como lugar privilegiado de intervenção para produção de uma realidade esvaziada de trans-travestifobia nos serviços de saúde, não se evidenciou produção científica direcionada a aprofundar essa discussão. Ao não se discutir compreensões por formação de trabalhadores de saúde (Qual formação? Que metodologias?), tal apontamento esvazia-se em sua possibilidade de, na formação de trabalhadores da saúde, provocar mudanças na realidade cotidiana dos serviços de saúde em favor da vida da população trans, uma vez que não será uma formação qualquer que produzirá efeitos em favor das vidas trans.

A escassez de recursos para o financiamento de políticas e programas voltados ao combate à discriminação de origem homofóbica e trans-travestifóbica, bem como a ausência da garantia de serviços específicos à população LGBT - como o processo transexualizador -, assumem protagonismo como barreira no acesso à saúde pela população trans. Nessa direção, Rocon, Silva e Sodré (2018, p. 446) argumentam que "o Estado, ao priorizar sua função de garantir a acumulação ao capital, tem enfrentado obstáculos à sua função de legitimação por meio da garantia dos direitos sociais, priorizando ações seletivas, focalizadas e hierárquicas". Nesse sentido, o subfinanciamento ou o não financiamento de ações estatais em favor das vidas LGBTs e, assim, o acesso universal à saúde pela população trans, também sofrerá rebatimentos do papel do Estado frente à acumulação capitalista com políticas de ajuste fiscal, garantia de superávits e redução dos direitos sociais. Há uma lacuna, nesse sentido, de produção científica que analise com destreza a relação entre decisões e políticas econômicas do Estado brasileiro com o financiamento das políticas públicas de saúde voltadas à população trans, como o processo transexualizador.

Por fim, a humanização também é apontada como diretriz ética e política que pode direcionar uma mudança importante na realidade dos serviços de saúde para a população trans. Borba (2014), nesse sentido, realiza uma ponderação primordial: apesar da Portaria n. 1707/2008, que institui o pro- 
cesso transexualizador, sinalizar como atendimento humanizado aquele que se faça livre de discriminação, para o autor, essa discussão que de maneira tímida aparece na portaria ministerial, insere-se em reflexões e proposições mais amplas situadas no movimento HumanizaSUS, na Política Nacional de Humanização do SUS (PNH). Nesse sentido, mais estudos sobre saúde trans, ancorados nas proposições, contribuições e movimentos éticos e políticos da $\mathrm{PNH}$, ainda se fazem necessários.

\title{
ACCESO A LA SALUD POR LA POBLACIÓN TRANS EN BRASIL: ENTRE LAS LÍNEAS DE LA REVISIÓN INTEGRANTE
}

\begin{abstract}
Resumen: En este artículo, se realiza un mapeo de la producción científica sobre el acceso a la salud por la población transexual después de 2008, un año importante para la salud trans en Brasil, en el cual se creó el Proceso Transexualizante del Sistema Único de Salud (Processo Transexualizador do Sistema Único de Saúde, en portugués). El objetivo de este trabajo fue realizar una revisión integrante de la literatura sobre el acceso a la salud de la población transexual y travesti brasileña, en las bases de datos MEDLINE, LILACS y SciELO, utilizando los siguientes descriptores: "transexualidad", "transexualismo", "travestismo", "travesti" y"transgénero", y se seleccionaron 22 artículos. Considerando la producción científica analizada, constatamos inúmeros desafíos al acceso de la población trans en el Sistema Único de Salud, como la discriminación, la patologización de la transexualidad, la falta de calificación de los profesionales, la acogida inadecuada, la escasez de recursos para el financiamiento de políticas y programas direccionados a la lucha en contra de la discriminación de origen homofóbica y trans-travestifóbica, así como la ausencia da garantía de servicios específicos - como el proceso transexualizante.
\end{abstract}

Palabras clave revisión integradora; acceso a la salud; travesti; transexual.

\section{Colaboradores}

Pablo Cardozo Rocon e Kallen Dettmann Wandekoken são responsáveis pela Concepção do artigo, produção e análise dos dados, redação de primeira e terceira versão, revisão final. Maria Elizabeth Barros de Barros, Marco José Oliveira Duarte e Francis Sodré participaram da redação da segunda versão e da revisão final. Todos aprovaram a versão final para publicação. 


\section{Referências}

ALMEIDA, Gilherme; MURTA, Daniela. Reflexões sobre a possibilidade da despatologização da transexualidade e a necessidade da assistência integral à saúde de transexuais no Brasil. Revista Latinoamericana Sexualidad, Salud y Sociedad, n. 14, p. 380-407, ago. 2013.

ARÁN, Márcia; MURTA, Daniela. Do diagnóstico de transtorno de identidade de gênero às redescrições da experiência da transexualidade: uma reflexão sobre gênero, tecnologia e saúde. Physis: Revista de Saúde Coletiva, Rio de Janeiro, v. 19, n. 1, p. 15-41, 2009.

ARÁN, Márcia; MURTA, Daniela; LIONÇO, Tatiana. Transexualidade e saúde pública no Brasil. Ciência \& Saúde Coletiva, v. 14, n. 4, p. 1.141-1.149, 2009.

BENTO, Berenice. Sexualidade e experiências trans: do hospital à alcova. Ciência \& Saúde Coletiva, v. 17, n. 10p. 2.655-2.664, 2012.

BENTO, Bento. A (re)invenção do corpo: sexualidade e gênero na experiência transexual. Rio de Janeiro: Garamond, 2006.

BORBA, Rodrigo. Sobre os obstáculos discursivos para a atenção integral e humanizada à saúde de pessoas transexuais. Revista Latinoamericana Sexualidad, Salud y Sociedad, n.17, p.66-97, 2014.

BORRILLO, Daniel. Homofobia: história e crítica de um preconceito. Belo Horizonte: Autêntica Editora, 2010.

BRASIL. Constituição da República Federativa do Brasil. Brasília: Senado Federal, 1988.

BRASIL. Ministério da Saúde. Carta dos direitos dos usuários da saúde. Brasília: Ministério da Saúde, 2006.

BRASIL. Ministério da Saúde. Portaria GM/MS n¹.707. Diário Oficial da União. 18/08/2008.

BRASIL. Ministério da Saúde. Portaria GM/MS n².836. Diário Oficial da União, 01/12/2011.
BRASIL. Ministério da Saúde. Portaria GM/MS n 2.803. Diário Oficial da União. 19/11/2013.

BUTLER, Judith. Desdiagnosticando o gênero. Physis: Revista de Saúde Coletiva, v. 19, n. 1, p. 95-126, 2009.

FERREIRA, Breno O. et al. Vivências de travestis no acesso ao SUS. Physis: Revista de Saúde Coletiva, v. 27, n. 4, p. 1.023-1.038, 2017.

FREIRE, Eduardo C. et al. A clínica em movimento na saúde de TTTS: caminho para materialização do SUS entre travestis, transsexuais e transgêneros. Saúde em Debate, v. 37, n.98, p. 477-484, 2013.

FOUCAULT, Michel. Em defesa da sociedade: curso no Collège de France (1975-1976). São Paulo: Editora WMF Martins Fontes, 2010a.

FOUCAULT, Michel. Os Anormais: curso no Collège de France (1974-1975). São Paulo: Editora WMF Martins Fontes, 2010b.

LIMA, Fátima; CRUZ Katlheen T. Os processos de hormonização e a produção do cuidado em saúde na transexualidade masculina. Revista Latinoamericana Sexualidad, Salud y Sociedad, n. 23, p. 162-186, 2016.

LIONÇO, Tatiana. Atenção integral à saúde e diversidade sexual no Processo Transexualizador do SUS: avanços, impasses, desafios. Physis: Revista de Saúde Coletiva, v. 19, n.1, p. 43-63, 2009.

LIONÇO, Tatiana. Que direito à saúde para a população GLBT? considerando direitos humanos, sexuais e reprodutivos em busca da integralidade e da equidade. Saúde e Sociedade, v. 17, n.2, p. 11-21, 2008.

MELLO, Luiz et al. Políticas de saúde para lésbicas, gays, bissexuais, travestis e transexuais no Brasil: em busca de universalidade, integralidade e equidade. Revista Latinoamericana Sexualidad, Salud y Sociedad, n. 9, p. 7-28, 2011. 
PAULA, Cristiane C.; PADOIN, Stela M. M.; GALVÃO, Cristina M. Revisão integrativa como ferramenta para tomada de decisão na prática de saúde. In: LACERDA, Maria R.; COSTENARO, Regina G. S (Org.). Metodologias da pesquisa para a enfermagem e saúde: da teoria à prática. Porto Alegre: Moriá; 2016. p. 51-76.

PINTO, Janaina J. et al. A medicalização e patologização na perspectiva das mulheres transexuais: acessibilidade ou exclusão social. Revista de Enfermagem UERJ, n. 25, p. 1-6, 2017.

POPADIUK, Gianna S.; OLIVEIRA, Daniel C.; SIGNORELLI, Marcos C. A Política Nacional de Saúde Integral de Lésbicas, Gays, Bissexuais e Transgêneros (LGBT) e o acesso ao Processo Transexualizador no Sistema Único de Saúde (SUS): avanços e desafios. Ciência \& Saúde Coletiva, v. 22, n. 5, p. 1.509-1.520, 2017.

RIBEIRO, Yara C. N. M. B.; CASTRO, Ricardo L.V. Acolhimento com classificação de risco: dois momentos de reflexão em torno das cores. In: BRASIL. Ministério da Saúde. Cadernos HumanizaSUS: Vol. 3, Atenção Hospitalar. $1^{\text {a }}$ ed. 2011.

ROCON, Pablo C. et al. (Trans)formações corporais: reflexões sobre saúde e beleza. Saúde e Sociedade, v. 26, p. 521-532, 2017.

ROCON, Pablo C. et al. Dificuldades vividas por pessoas trans no acesso ao Sistema Único de Saúde. Ciência \& Saúde Coletiva, v. 21, n. 8, p. 2.517-2.526, 2016.

ROCON, Pablo C. Quando os corpos trans adentram o processo transexualizador: experiências que conformam a transexualidade. Dissertação (Mestrado em Saúde Coletiva). Centro de Ciências da Saúde. Vitória: Universidade Federal do Espírito Santo, 2018.

ROCON, Pablo C.; SILVA, Adriana I.; SODRÉ, Francis. Diversidade de gênero e Sistema Único de Saúde: uma problematização sobre o processo transexualizador. SER Social, v. 20, n. 43, p. 432-448, 13 nov. 2018.
ROCON, Pablo C.; SODRÉ, Francis; RODRIGUES, Alexsandro. Regulamentação da vida no processo transexualizador brasileiro: uma análise sobre a política pública. Katálysis, v. 19, n. 2, p. 260-269, 2016.

ROMANO, Valéria F. As travestis no Programa Saúde da Família da Lapa. Saúde e Sociedade, v. 17, n. 2, p. 211-219, 2008.

SAMPAIO, Liliane L. P.; COELHO, Maria T. A. D. Transexualidade: aspectos psicológicos e novas demandas ao setor saúde. Interface: Comunicação, Saúde, Educação, Botucatu, v. 16, n. 42, p. 637-49, 2012.

SEHNEM, Graciela D. et al. Assistência em saúde às travestis na atenção primária: do acesso ao atendimento. Revista de Enfermagem UFPE, v. 11, n.4, p. 1.676-1.684, 2017.

SILVA, Francisco A.; MELLO, Ivana S. P. B. Psicologia e despatologização da transexualidade. Tempus, actas de saúde coletiva, v. 11, n. 1, p. 81-95, 2017.

SOUZA, Martha H. T. et al. Violência e sofrimento social no itinerário de travestis de Santa Maria, Rio Grande do Sul, Brasil. Cadernos de Saúde Pública, v. 31, n.4, p. 767-776, 2015.

SOUZA, Martha H. T. et al. Itinerários terapêuticos de travestis da região central do Rio Grande do Sul, Brasil. Ciência \& Saúde Coletiva, v. 19, n. 7, p. 2.277-2.286, 2014.

SOUZA, Martha H. T.; PEREIRA, P. P. G. Cuidado com saúde: as travestis de Santa Maria, Rio Grande do Sul. Texto \& Contexto Enfermagem, v. 24, n.1, p. 146-153, 2015.

SPIZZIRRI, Giancarlo; ANKIER, Cila; ABDO, Carmita H. N. Considerações sobre o atendimento aos indivíduos transgêneros. Revista Diagnóstico e Tratamento, v. 22, n. 4, p. 176179, 2017. 